in front. The majority (86\%) reported that it was somewhatextremely unlikely they would be caught by police if following too closely, indicating a perceived lack of enforcement for this offence. Reasons for this included perceptions of difficulty for police to enforce this offence (5\%), not having heard of anyone being caught for this offence $(17 \%)$, and other police priorities (30\%).

Conclusions This study is part of a larger research project that aims to improve knowledge about driving conditions, patterns and locations, and driver behaviours that lead to driving at unsafe headways (i.e. following too closely). Recommendations for use of these findings to inform driver education and awareness campaigns are discussed.

\section{INFLUENCE OF THE BUILT ENVIRONMENT ON CRASHES INVOLVING PEDESTRIANS IN COMPLEX URBAN AREAS}

Karen Stephan, Stuart Newstead. Monash University Accident Research Centre, Australia.

\subsection{6/injuryprev-2016-042156.861}

Background On urban roads, road users interact in a highly complex environment. Few previous multivariable studies investigated the association between the built urban environment (including the road, roadside and human activity) and crashes. Roadside design and amenities and facilities that impact road user movements were rarely considered. This research aimed to identify characteristics of the built urban environment associated with the frequency of pedestrian-vehicle casualty crashes (PVC) on shopping strips in metropolitan Melbourne, Australia.

Methods The study had a cross-sectional design. Strip shopping arterial road segments in Melbourne, Australia, were identified $(\mathrm{n}=142)$. Data were collected for a broad range of potential risk factors relating to the road, roadside and human activity. Analysis using Poisson regression identified factors associated with PVC frequency. Diagnostic tests were conducted to assess model fit.

Results From 2005 to 2009 there were 519 (median $=5.4 / \mathrm{km}$ ) PVC on the 142 midblock road segments. Aspects of the built environment associated with increased PVC frequency were: road width, unsignalised intersections, medians or traffic islands, midblock pedestrian crossings, roadside development height, offstreet parking facilities, establishments with a late night liquor license, railway stations and tertiary education institutions. Lane width and parking clearways were associated with significant reductions in PVC. Speed limits were associated with PVC in a non-linear fashion. There was no association between traffic volume or estimated pedestrian activity and PVC.

Conclusions A range of risk factors were related to PVC on strip shopping road segments including traditionally studied characteristics like road design and less commonly studied aspects such as the roadside and facilities and amenities on the road segment. This study can contribute to the design of PVC countermeasures and better risk assessment tools for urban road segments.

\section{MYANMAR ROAD SAFETY SITUATION 2015: AN URGENT ISSUE FOR THE NATION}

\footnotetext{
${ }^{1,2}$ Chamaiparn Santikarn. ${ }^{1}$ Ex-WHO South- East Asia Regional Office (SEARO), India; ${ }^{2}$ WHO Office, Myanmar
}

10.1136/injuryprev-2016-042156.862
Background The estimated road traffic injury death rate in Myanmar increased rapidly from 15 per per 100,000 pop in 2013 to 20.3 in 2015 . This recent death rate is $2^{\text {nd }}$ only to Thailand within the Region. A great change from the $6^{\text {th }}$ rank in 2013.

Description of the problem and activities In 2015, the policy maker in the WHO SEARO being informed of the rapid increase reacted in response to the informtion by reassigning the Regional advisor to Myanmar WHO office and mobilised 16,000 USD for intervention. With the seed money and limited time available, a multisectoral road safety project was initiated by the WHO office and the injury prevention focal point from the $\mathrm{MOH}$ with the focus on the Yangon - Nay pyi taw - Mandalay Express highway due to the more public awareness and concerned at the national level.This will serve as a pilot project for a larger scale intervention afterwards.the project has very tensed time limitation to finalise all activties within less than 6 months. The project started with a multisectoral meeting among important stakeholders. This already has drawn the attention of the media was news was disseminated.The frame work of the project is the 5 pillars of the Decade of Action for Road Safety 2011-2020. The major activities of the project are 1) close and regular collaboration with the National road safety committee, the transport and police authority 2) secondary data collection from existing combine data sources 3) road safety data workshop 4) journalist workshop 5) "Black Spot" road signage project 6) training of traffic police trainers on preventing road traffic injuries. 7) workshop on strategy development on road safety in collaboration with the ADB.

Results The activities are ongoing. The output, outcome, impact and lessons learned will be presented in the conference.

Conclusions Myanmar road safety situation 2015 is an urgent issue for the nation.

\section{UNDERSTANDING THE PROFILE OF INJURIES FOR VULNERABLE ROAD USERS: A DATA LINKAGE STUDY}

Angela Watson, Ross Blackman, Kirsten Vallmuur, Barry Watson. Queensland University of Technology (QUT), Centre for Accident Research and Road Safety - Queensland, Australia

\subsection{6/injuryprev-2016-042156.863}

Background Unless substantial gains are made in the prevention of road crashes, they will become the third ranked global burden of disease and injury by 2020. A growing proportion of this burden relates to vulnerable road users (e.g., motorcyclists, cyclists, and pedestrians). In order to reduce this burden, there is a need to fully understand the nature and contributing circumstances of crashes and the resulting injuries. While police-reported crash data contain detailed information about crash circumstances, they lack accurate information about the severity and nature of injuries which are included in hospital data. By bringing these data collections together using data linkage, the relationship between the characteristics of vulnerable road user crashes and their resulting injuries were explored.

Methods Data from the Queensland Road Crash Database (QRCD) and the Queensland Hospital Admitted Patients Data Collection (QHAPDC) for the year 2010 were linked. There were 1,382 police-reported motorcyclist injuries that linked to a hospital record (42\% of all police-reported motorcyclist injuries), 429 cyclists (25\%), and 644 (39\%) pedestrians. The relationships between crash characteristics such as counterpart involvement, alcohol, fatigue, speed, and helmet use and injury severity (e.g., 
ICD-derived Injury Severity Score ICISS, length of stay), nature, and body region were examined.

Results The involvement of motor vehicles was related to more severe injury outcomes for vulnerable road users (between 1.5 and 2.8 times the odds of being serious), as were high speeds (between 1.2 and 1.6 times), alcohol (2.1 times for motorcycles), and helmet non-use (between 1.9 and 2 times). The circumstances of crashes, such as counterpart type and crash location, influenced injury nature and body region.

Conclusions By bringing together circumstance data from police and injury outcome data from hospitals, a greater understanding of the link between crash circumstances and injury outcomes was achieved. Studies using linked data can better inform intervention and treatment for a more holistic approach to the reduction of road trauma for vulnerable road users.

\section{SPEED CONTROL ON MITRAPHAP HIGHWAY WHICH PASSING THROUGH THE MUNICIPALITY OF KHON KAEN PROVINCE BY AUTOMATIC SPEED ENFORCEMENT SYSTEM}

Nittayaporn Srihabua. Khon Kaen Hospital, Thailand

10.1136/injuryprev-2016-042156.864

Background Mitraphap highway is passing through Khon Kaen municipality. The passing length is 14 kilometres. Every year, there are an average of 500 road crashes and at least 15 road accident fatalities occurring on this road. The most common cause of road accidents in this area is related to drivers driving at speeds above the legal speed limit.

Ojectives to reduce vehicle's speed on the 14 kilometres of the Mitraphap highway which passing through Khon Kaen's municipality in order to reduce number of crashes and severity in this high risk area.

Methods Participation Action Research Methodology is used for this project. The research was carried out in 8 steps between January and December 2015. Step 1: Set up a working committee to conduct continuous meetings and implementation. Step 2: Working committee studies high risk areas on Mitraphap highway. Step 3: Use data analysis plan for solutions together. Step 4: Communicate data analysis with key stakeholders. Step 5: Execute prevention measures according to plan by 5.1) setting speed limit to $60 \mathrm{~km} / \mathrm{hr} 5.2$ ) campaign measures to detect driving speed 5.3) Educate on speed control and road traffic injury prevention 5.4) Instal traffic signs and billboard on the road 5.5) instal automatic speed detector cameras ( $24 \mathrm{hr}$.) and charge speed violators. Step 6: Intensive public campaign. Step 7: strict enforcement. Step 8 Analysis for the result of the implementation: The team evaluated effectiveness of the campaign by conducting data analysis and assessed attitudes of drivers toward measures to control driving speed in the controlled areas through face-to-face interviews.

Results $87 \%$ were in favour of enforcing speed limit. $79 \%$ were in agreement of using automatic speed detector cameras. $78 \%$ said they were aware of the speed limit enforced at $60 \mathrm{~km} / \mathrm{hr}$ and $75 \%$ agreed that this is an appropriate speed limit. Prior to enforcing the campaign measures, data revealed that in 2014 there were 559 road accidents with 542 injuries and 22 fatalities. After implementing the campaign measures in 2015, number of road accidents reduced to 355 incidents, road accidents injuries reduced to 296 cases $(\mathrm{OR}=0.24,95 \% \mathrm{CI}:=0.13-0.43)$ and fatalities reduced to 9 cases $(\mathrm{OR}=0.74,95 \% \mathrm{CI}:=0.341 .63)$. Further, in 2015 a total of 4,442 speeding tickets were issued and $69.05 \%$ of violators paid their fines.

Conclusions Results revealed that by using data to plan road accident prevention activities and develop participation of network parties to prevent and solve problems related to road accidents can reduce number of incidents and severity in this high risk area. Further, this activity also strengthened the ability among the network parties and working committee to be able to prevent and solve problems related to road accidents in other high risk areas which should be further implemented on a continuous basis.

\section{BURDEN OF ROAD TRAFFIC INJURIES IN THIKA AND NAIVASHA, KENYA}

${ }^{1}$ Abdulgafoor M Bachani, ${ }^{1}$ Yuen Wai Hung, ${ }^{2}$ Daniel Akunga, ${ }^{3}$ Stephen Mogere,

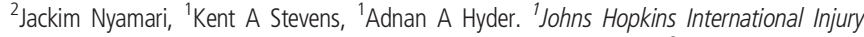
Research Unit, Johns Hopkins Bloomberg School of Public Health; ${ }^{2}$ Kenyatta University; ${ }^{3}$ Roless Institute, Kenya

\subsection{6/injuryprev-2016-042156.865}

Background Road traffic injuries (RTIs) have become one of the leading public health burden in low- and middle-income countries (LMICs). Studies have found RTIs were among the major causes of death and hospital admissions in Kenya. However, most findings were from health care settings and there is a lack of literature on population-based estimates of the burden of road traffic injuries in Kenya.

Methods A cross-sectional household survey was conducted in Thika and Naivasha, Kenya in 2011. Using a cluster random sampling approach, households in the area served by six to eight community health units in the two districts were randomly selected for interview. Upon informed consent, interviewers asked adult respondents about all unintentional injuries to them or members of their households in the past one year, followed by type of injury, and place of occurrence. Additional questions were asked about the road traffic injury or death, if a road traffic injury was reported.

Results The study recruited 669 households in Thika and 439 households in Naivasha, which included a total of 3804 individuals. A small proportion of households approached declined the interview $(2.3 \%$ in Thika, $10.0 \%$ in Naivasha). Unintentional injuries were prevalent in both districts (7.3 in Thika, 5.9\% in Naivasha). RTIs were the top cause of unintentional injuries in Thika (46.8\%), and the second cause of unintentional injuries in Naivasha (27.3\%). Majority of individuals with RTIs sought medical treatment after the injury in Thika (96.5\%), but fewer RTI survivors sought care after RTIs in Naivasha (73.1\%). Reporting of the RTI to police was also low in Naivasha $(66.1 \%$ in Thika vs. $34.6 \%$ in Naivasha).

Conclusions This survey provides a better understanding of the prevalence of RTIs in Thika and Naivasha, the circumstances leading to them, as well as medical care for the injury. This information could be useful in designing and implementing interventions to address this burden. 